\title{
Estimation of possible ecological effects of Chernobyl NPP to the environment as a result of shutting-down of CHNPP
}

\author{
Yu.A. Ivanov, V.I. Kholosha', A.N. Arkhipov, V.V. Derevets, S.I. Kireev, N.I. Proskura' \\ V.E. Tepikin, E.G. Buntova, N.D. Kuchma, A.A. Zalissky and S.A. Paskevych \\ Chernobyl Radioecological Center, Shkolnaya Str. 6, 07270 Chernobyl, Ukraine \\ ${ }^{1}$ State Department, Administration of the Exclusion Zone and the Zone \\ of Absolute Resettlement, Sovetskaya Str. 14, 07270 Chernobyl, Ukraine
}

\begin{abstract}
The problems, which should be analysed and decided in detail for adequate estimation of ecological effects of the ChNPP as well as activities for its shutting-down on the environment are considered. Particularly, these are: nuclear safety control of staff, population and environment during all stages of the ChNPP closing; maintenance of minimal ecological effect on the environment; development of scientific justify programs of radioecological monitoring on the territory of the ChNPP near zone for obtaining the adequate operating information and forecast of radioecological situations during realisation of activities; development and estimation of effectiveness of technologies for recultivation and remediation of territories technogenically changed as a result of activities; development of technologies and design solutions. They provide reliable environmental protection from radioactive materials during all ChNPP closing operations; estimation of modern radioecological situation of ChNPP cooling pond, estimation of various scenario its further maintenance after ChNPP closing, etc. An analysis of parameters of radiological situation on the Exclusion zone, including estimation of sources and fluxes of long-lived radionuclides both inside and outside its borders, it was showed that ChNPP closing would not cause significant change of intensity and direction of longlived radionuclide fluxes. Nevertheless, ChNPP closing predetermines a change of a state of some sources (in particular, pond-cooler) and origins new (storehouse of a spent nuclear fuel, enterprises on processing of solid and liquid radioactive waste, etc). Changes in a condition of these sources (even at exception of consideration of extreme meteorological conditions and emergencies) are put with a number of new problems, requiring solution. Possible radioecological and ecological problems both of the Exclusion zone and the territory that arranges near to it, which could be appeared dealing with Chernobyl NPP closing are discussed.
\end{abstract}

\section{NNTRODUCTION}

The complex of work, directed to ChNPP shut down requires a solution of a series of scientific and fechnical problems. In the concept and program of the ChNPP shut down it have been declared requirement of registration of an actual ecological condition in the Exclusion zone, population and staff safety necessity, minimisation of perspective ecological affects for environment during realisation of all work stages. Special attention to this ecological action will be determined.

Problems connected to evaluation of ecological influence during ChNPP closing should be in details worked and include:

- Safety of staff, population and environment during all stages of removal ChNPP from maintenance.

- Development of scientific - justify programs of radiation - ecological monitoring of near ChNPP zone territory for obtain of adequate information and for prognosis of development radiation ecological situations during realisation of ChNPP shut down.

- Development and evaluation of effectiveness of engineering processes of remediation and rehabilitation of artificial changed territories after ChNPP shut down.

- Development of engineering processes and design solutions, which ensure a reliable protection of environment from radioactive substances at all operations of ChNPP shutting down.

- Complex solution of Exclusion Zone water protecting problem and evaluation of modern radiation - ecological condition of ChNPP cooling pond.

- Development of conceptual base and normative documents on indicated problems.

The choice of optimum variant of measures directed on a risk level and harm decrease, should be carried out on a base of their economic and ecological evaluation. As a criterion of such evaluation it is sensible to use cost indexes of radiation doze saved as result of protective measures realisation. 


\section{RADIONUCLIDE FLUXES OUT OF EXCLUSION ZONE}

Generalisation of results of complex researches in Exclusion zone have allowed to evaluate of significance different radionuclide migration paths out of Exclusion zone:

- Water river flux (river Pripyat) - up to $0.09 \%{ }^{137} \mathrm{Cs}$ and up to $0.6 \%{ }^{90} \mathrm{Sr}$ of total amount on Exclusion zone territory or $80-97 \%$ of total out-flux of these radionuclides by all migration paths.

- Air (wind) transposition - up to $0.004-0.02 \%$ of total amount on Exclusion zone territory or 5 $15 \%$ (in case of forest fires - up to $20 \%$ ) of total out-flux of these radionuclides by all migration paths.

- Biogenic out-flux is up to $0.001 \%{ }^{137} \mathrm{Cs}$ and $0.0006 \%{ }^{90} \mathrm{Sr}$ of total out-flux of these radionuclides by all migration paths.

- Technogenic migration - from 0.002 up to $0.8 \%$ of total out-flux of these radionuclides by all migration paths.

In $1992{ }^{90} \mathrm{Sr}$ out-flux by river Pripyat with an underground drain was appreciated less than $0.06 \mathrm{TBq}$ (1.6 Ci). In 1996, radionuclide underground out-flux from water collection territories of near ChNPP zone was evaluated in a thousands part of $\mathrm{Ci}$ per one year. ${ }^{90} \mathrm{Sr}$ integrated out-flux with underground drain from surface reservoirs of near ChNPP zone for 300 years is evaluated in $15 \mathrm{TBq}(420 \mathrm{Ci})$, or $3 \%$ of initial total stock in water reservoirs. So, ${ }^{90} \mathrm{Sr}$ hydro-geological migration from places of radioactive waste stock cannot lead to fatal out-fluxes to $r$. Pripyat.

In 1997, according to available evaluations, total release of long-term radionuclides (so named "organised" release) from the "Shelter" has formed 10.6 GBq (284 mCi). Radioactive aerosol release through holes of "Shelter" (unorganised release) of alpha - emitting radionuclides i.e. isotopes of plutonium, americium-241 have formed $18.5 \mathrm{MBq}(0.5 \mathrm{mCi}),{ }^{134,}{ }^{137} \mathrm{Cs}-480 \mathrm{MBq}(13 \mathrm{mCi})$, the total release of radioactive substances has formed $605 \mathrm{MBq}(16.3 \mathrm{mCi}$ or $0.64 \%$ of the permissible amount), So, in normal state (accident-free) of "Shelter", radionuclide fluxes from it are by three orders of magnitude less with comparison of water out-fluxes of radioactive substances from Exclusion Zone.

In conditions of normal (accident-free) ChNPP maintenance the total radionuclide out-fluxes with gas-aerosols makes about $7.4 \mathrm{TBq}^{*} \mathrm{y}^{-1}\left(2 \mathrm{Ci}^{*} \mathrm{y}^{-1}\right)$, that is much lower than radionuclide fluxes with water drain and wind transposition.

\section{DRAINING OF A COOLING-POND}

ChNPP cooling-pond is the largest reservoir of the Exclusion Zone and its ecosystems after the 1986 accident have been exposed to significant radioactive contamination.

Cooling-pond is a reservoir by square $22.9 \mathrm{~km}^{2}$, the water stock here is $160-\mathrm{mlm} \mathrm{m}^{3}$, specific ${ }^{137} \mathrm{Cs}$ activity in water in $1990-2000$ changed in limits $12.2-2.8 \mathrm{~Bq}^{*} \mathrm{~L}^{-1},{ }^{90} \mathrm{Sr}-8.5-2.3 \mathrm{~Bq}^{*} \mathrm{~L}^{-1}$. The total ${ }^{137} \mathrm{Cs}$ activity of bottom sediments reaches $160 \mathrm{TBq}(\sim 2.7$ thousands of $\mathrm{Ci})$, TUE $-5 \mathrm{TBq}(135 \mathrm{Ci})$. Cooling. pond contribution in total radionuclide out-fluxes makes $6-10 \%$ approximately [2].

Distribution of silt (accumulators of radionuclides) on bottom surface is extremely irregular, the essential part of silt - 40-50\% - is concentrated in reductions of old river channels, former riverbed. It is need here to create plant cover on pond bottom as protecting measure.

\section{COOLING-POND DRAINAGE}

Cooling-pond drainage is reflecting an ecological situation of neighbouring biocenoses, which are presented here by water-saturated ground, deciduous and coniferous forests. Taking into account such conditions and presence of Dniper reservoir system it is easy to see that all vegetative complex is patched 
up of different plant species. Lowland melioration of the 70-80-ies has had significant influence on local forestation, especially on oaks forest all along of Dniper reservoir system.

Soil water reducing can have an influence on near flood-land forest, which formed of alder and different willow species. The most of all oak forests located on left bank of Dniper reservoir can suffer of water regime change and it there were noted in Paryshev and Mashev forest division. As is well known any phytocenosis state can be worsening by ecological condition including affection by diseases and vermin. In this connection it is necessary to increase the phyto-sanitary control in those forests.

\section{ENVIRONMENT}

Phyto-cenosis alteration has undoubtedly an influence on vegetable species and numerous structures of all fauna systems. Disturbance of ecological conditions changes forage reserve for many birds and can bring to their quantity reduce up to their disappearance [1]. For example erne (the Red Book); according with our and literary information its quantity in cooling pond region is the greatest one that is registered in Ukraine. Its amplitudinous spreading here is connected with rich forage reserve (fish nutrition) and absence of human disturbance. Cooling-pond destruction and consequently decrease of forage reserve can greatly influence on this rare species.

Natural conditions and a ChNPP operating regime have an influence on aquatic life and cooling-pond ecosystems.

ChNPP influence proves itself, first of all with direct action on temperature and pond hydrological regime. Variable parameters of ChNPP activity specify fish species quantity and their correlation, forming of cooling-pond ecosystem structure.

Combination of ChNPP influence and natural factors determine specific variety and stocks of a biomass in cooling-pond, and they are presented in Table 1.

Table 1. Approximate stores of basic biotic components of cooling-pond (in Ton)

\begin{tabular}{|l|c|c|c|}
\hline & Min & Max & Presumable value \\
\hline Fish species & 900 & 12000 & 8000 \\
\hline Surface vegetation & $120^{*}$ & $>2500^{*}$ & $1200^{*}$ \\
\hline Underwater vegetation & $1000^{*}$ & $20000^{*}$ & $10000^{*}$ \\
\hline Two folding molluscs & 600 & 60000 & 30000 \\
\hline Planktons & $300^{*}$ & $20000^{*}$ & $3000^{*}$ \\
\hline
\end{tabular}

* The number and mass during season can vary in 100 and more time.

In case of cooling-pond water stock reduces from river Pripyat (about $1.3 * 10^{8} \mathrm{~m}^{3}$ per one year), its area can be reduced in 4-5 times. There are about $15 \mathrm{~km}^{2}$ highly radioactive bottom sediments that will be exposed, all aquatic plant and higher water plants, almost all molluscs (basically dreyssen) and majority of remaining benthos, fair amount of fish will perish practically.

Hydrobionts will disappear because of varying of condition, among them are pelagolimnofill, litoreofill and other fishes species.

Other negative factors of negative action on environment will be modification of ground water level in reservoir region, radionuclide drain accumulation to new reservoir's places, biological and atmospheric radionuclide fluxes out of limits of former pond-bed.

Chemical structure of water and other components will vary with decrease of dilution and disintegration of pond water organic. As result, thousands tons of biomass, doubtless, will make worse sanitary state of the region in ten times, it is possible in hundred times.

On the other hand, properly uniqueness of the cooling-pond complicates prognosis of radionuclide behaviour and state of biota. Today, it is impossible to foresee definitely a character of development of 
events in cooling-pond. Only continuous ecological and radiation monitoring can give correct evaluation of running processes in this ecosystem.

Modification of radiological and ecological parameters, directness and intensity of radionuclide fluxes as result of cooling-pond discharge, construction and commissioning of new industrial plants predetermine necessity of radioecological and ecological (phyto and zoo sanitary) monitoring in region of cooling-pond, monitoring of secondary resuspension and wind transposition of radionuclides.

\section{CONCLUSION}

Unfavourable action of above-mentioned factors on the nature objects both inside exclusion zone and near territory modify also factors of non-radiation nature, in particular, characteristic of phyto-sanitary state on exclusion zone.

It is necessary for decision of radiation situation problem on territory of Exclusion Zone:

- Probability of emergency during base works on "Shelter" has to be to reduce to zero;

- Main directions of work on natural and technogenic objects in zone, where it is difficult to reduce probability of extreme situation, are development and the realisation of organisational engineering measures on decrease of their radiation action (preventing of wash-out in high water phase, fire prevention measures in woods, monitoring of unauthorised use of Exclusion Zone objects);

- Analysis of presented assessments shows, that danger of the ChNPP during realisation of all shut down works will not lead to significant change of intensity and directions of fluxes of long-term radionuclides inside zone and out of its borders.

However, the ChNPP shut down predetermines change of some other radioactive sources, in particular, cooling-pond and appearance of new ones (radioactive waste storage, radioactive waste reprocessing factory, etc). Changes of these sources condition are new tasks requiring solution.

\section{References}

[1] L.I. Frantsevich, A.D. Komissar, A.A. Yermakov, and al. - Assessment of the radionuclides carrying out by animals - migrators. Reports of the First All-Union Scientific and Technical Meeting on the Results of the Liquidation of the Consequences of Chernobyl NPP Catastrophe/Editor Ye. I Ignatenko. Vol. 3, Part II/ p.p. 110-123.

[2] National Report of the Ukraine "10 years after the accident at Chernobyl NPP" Minchornobyl, Kiev. 1996 - p. 250.

[3] Conception of the Chernobyl Exclusion Zone at the territory of the Ukraine, Kiev, 1995.

[4] The Law of the Ukraine "The legal status of the territory which was radioactively contaminated due to the Chernobyl catastrophe" dated 27.02.91 No 791a-XII. 